\title{
Investigation of Aerodynamic of Expand Folding Rudder Separator Delivery from Cavity
}

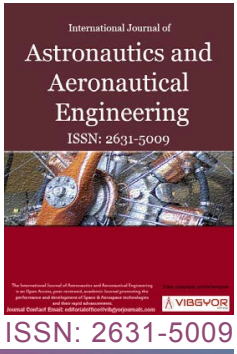

\section{Xue Fei ${ }^{1 *}$, Jin Xin ${ }^{2}$ and Wang Yuchao ${ }^{1}$}

${ }^{1}$ China Academy of Aerospace Aerodynamics, China

${ }^{2}$ AVIC Chengdu Aircraft Design \& Research Institute, China

\begin{abstract}
In the subsonic, transonic and supersonic wind tunnels, the launching test technology of the buried separators in folding rudder separator is studied. In view of the two different folding modes of the Separator rudder surface, two testing techniques are developed for the horizontal folding and vertical folding of the rudder surface, which can ensure the self locking function before and after the rudder surface is unfolded. The folding and unfolding state is not affected by the start impact of the wind tunnel and the turbulence. At the same time, the position of the rudder surface is expanded to achieve the real launch and expansion of the simulated separator. The developed dual angle of view, high brightness optical path system and six degree of freedom image analysis system can obtain the full trajectory image and aerodynamic parameters of the projectile embedded in the aircraft. The test technology can independently adjust the ejection speed and angular velocity of the release material, and can study the influence of different separation conditions on the separation safety. The non-expansion test technology of the rudder surface has completed the wind tunnel test verification under the condition of supersonic velocity and multi-body interference and complex aerodynamic force, which meets the demand of the launch and wind tunnel test research.
\end{abstract}

\section{Keywords}

High speed separator delivery, Folding rudder separator, Separator firing from cavity, Carrier and separator interference, Multi-bodies separation, Six degree of freedom

\section{Introduction}

Delivery from cavity has many advantages, including reducing the rate of radar discovery, reducing the aerodynamic drag and increasing the range of the bomber [1-4]. However, the size of the interior of the aircraft is often limited. How to make better use of the space in the cabin and as much as possible to mount the separator is an important means to evaluate the level of the combat effec- tiveness of the aircraft. At the same time, in order to make the separator flight more flexible and controllable, the steering surface of the separator is often relatively large. The rudder surfaces are also out of the separators $[5,6]$, occupies too much space in the cabin when the separator is suspended in the cavity, causing the extreme waste of the space in the cabin and greatly reducing the combat effectiveness of the aircraft. The folding rudder is

*Corresponding author: Xue Fei, China Academy of Aerospace Aerodynamics, China

Accepted: May 25, 2020; Published: May 27, 2020

Copyright: (C) 2020 Fei X, et al. This is an open-access article distributed under the terms of the Creative Commons Attribution License, which permits unrestricted use, distribution, and reproduction in any medium, provided the original author and source are credited.

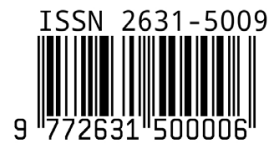

Fei et al. Int J Astronaut Aeronautical Eng 2020, 5:038 
a good way to save space and increase the loading number of the separators, and has been successfully applied to separators [7-9], such as the folding rudder used for shipborne separator, the roll arc wing used by the antitank projectiles. The space of the airborne embedded projectile is limited, and if the folded rudder is applied to the embedded Separator, it will make full use of the limited space in the cabin to greatly improve the operational capability of the fighter.

There is still uncertainty in the launching of the fixed rudder surface Separator [10-14], and the folding rudder Separator needs to carry out the unfolding of the rudder when it is close to the machine. The launching of the rudder must cause the change of the aerodynamic force and torque of the projectile, and the trajectory of the Separator is difficult to be determined [15-18]. A series of complex conditions are added to the complex flow interference area, making the separation characteristics of the folded rudder Separator more difficult to determine [19-23]. Therefore, it is very necessary to carry out dynamic test research on the factors affecting the deployment of buried separators in folding rudder separator.

\section{Technical Difficulties}

\section{Ejection technology}

We need to solve the problem that the model hangs. It is well known that the impact load of the wind tunnel is very large. For dynamic test, the model mechanism is active, which requires that all the moving parts before the test start to lock themselves to prevent the impact load to start the test mechanism and cause the failure of the test. Specifically, the moving parts of the project include the Separator launching mechanism and the rudder folding rudder deployment mechanism. The 2 parts require self-lock and unlocking design; especially the folding rudder needs to simulate real launch process, not only need self-lock before unfolding, but also require locking function after unfolding. It is easy to imagine the difficulties of designing so many functions small separators, which just like a ballpoint pen.

The model ejection $v$ and $\omega$ need to be independent and continuously adjustable. This requires the ejection mechanism to have the ability to adjust the ejection speed and angular velocity independently, which puts forward a very high demand

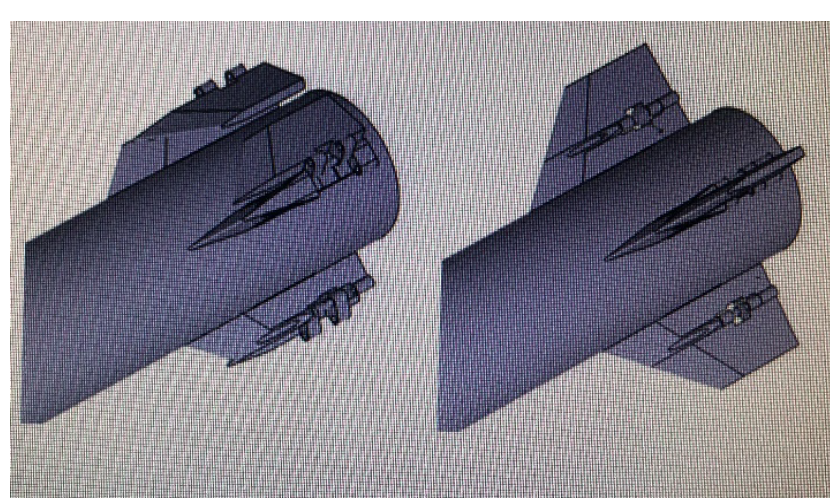

Figure 1: Folding and unfolding of parallel folding rudder surface.

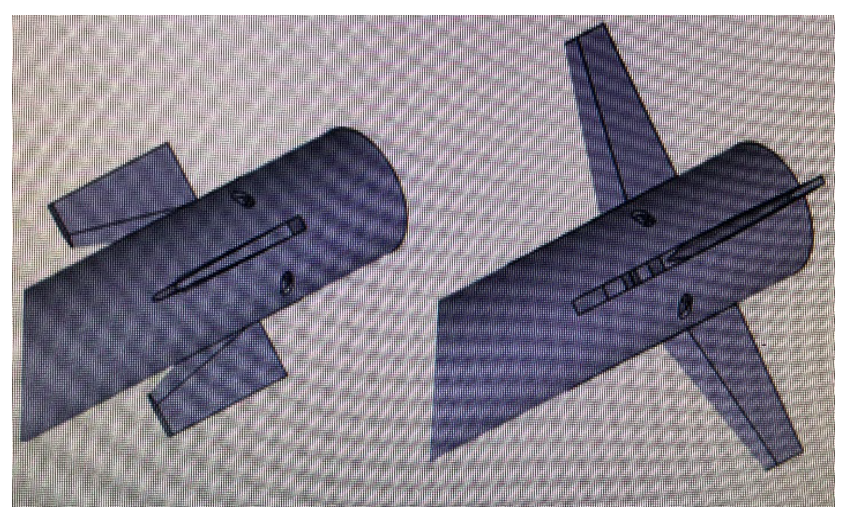

Figure 2: Folding and unfolding of vertical folding rudder surface.

for the reliability of the separation mechanism.

\section{Folding rudder unfolding technology}

The model ejection velocity and angular velocity need to be independent and continuously adjustable. In order to solve the problem that the separator can hold, the problem that the separator can be unlocked when it needs to be unlocked should be solved, and the speed and angular speed of the separator should have certain accuracy. At the same time, in order to find the appropriate separation velocity and angular velocity, the separation velocity is usually fixed and adjusted separately in the test, which requires the ejection mechanism to have the ability to independently adjust the ejection velocity and angular velocity, which puts forward a very high requirement for the reliability of the separation mechanism.

The foldable rudder can be divided into 2 types: Parallel folding rudder and vertical folding rudder. Parallel is parallel to the axis of the projectile body, as shown in Figure 1. The vertical folding refers to 
the vertical axis of the steering axis and the axis of the body, as shown in Figure 2.

\section{Solution and Implementation Plan}

\section{Ejection mechanism}

The ejection speed is provided by a single cylinder. On the basis of the ejection mechanism, the angular velocity adjustment device is designed to realize the independent continuous regulation of the ejection velocity and angular velocity of the model. When the ejection cylinder moves down the ejection model, the angular velocity regulator works at the same time, making the model have the presupposed ejection speed and angular velocity at the moment of departure from the ejection frame.

The model adopts hole pin coordination, opening holes in the model hooks, and opening holes in the corresponding positions of ejection rack points. After the model hole corresponds to the hanging hole, the steel wire is locked. The principle of its control is that the cross section of the projectile is "7" shape. A "L" lever is designed on the catapult hanger. After the hanger is hung up, the ejection frame is moved up with the ejection frame. After the ejection frame is moved up, the piston rod is locked with the bolt. At this time, the "L" lever on the hanger has turned in place in the movement and just locked the bomb. The "7" type hook on it. The model is locked. When ejection, the piston bolt is pulled out, the ejection rack moves down, the "L" lever is returned, and the contact is disconnected from the "7" type hook on the projectile, and the model is unlocked.

Table 1 shows the test results and accuracy of ejection for 3 consecutive ejection stages. The expected ejection angle is 300 degrees/sec and the speed is $2.28 \mathrm{~m} / \mathrm{s}$. we can see that the speed and angular velocity error of the ejection mechanism for 3 consecutive ejection separator meet the technical requirements, with a repetition rate of $100 \%$. The speed, angular velocity, error and repeatability of the test set meet the technical requirements.

\section{Rudder surface expansion technology}

In the design of parallel folding rudder, the model folding tail rudder is locked with a ring card. It can resist the turbulence started by the wind tunnel and use the pullout to trigger the unfolding of the rudder surface. When the folding rudder model is separated from the distance from cavity, the pullout line reaches the limit length, thus pulling out the pin out and triggering the moving mechanism within the projectile. The folding rudder is expanded, and the folded rudder is expanded by the reserved torsional force of the spring to prevent the airflow from blowing and folding the expanded rudder. At the same time, it is necessary to explain that the center of mass of the separator is removed and the high degree of finish is removed, which minimizes the effect of the drawing operation on the movement of the projectile. Figure 3 and Figure 4 show the test images of two test models in windless state. To verify the feasibility of model unlocking and rudder deployment test technology.

\section{Image data analysis method}

The desired image is obtained through background subtraction, median filtering, shadow removal, mathematical morphology processing and connected domain analysis. The $x, y, z$ coordinates, pitch angle and yaw angle of the centroid of the model are identified through the elevation and elevation view, and the rolling angle of the model is obtained by model matching.

Image recognition is a key technology of this test technology, which is affected by factors such as image definition, pixel location, target location method and model boundary recognition algorithm.

As the direct source of data analysis, the accuracy of model angle identification is higher and the accuracy of data analysis is more accurate. As shown in Table 2, the accuracy of this attack angle analysis can be controlled within 0.2 degrees. The true value is the true angle value of the fixed attack angle of the model, and the identification value is the angle value identified after the camera is captured.

Table 1: The results of ground test.

\begin{tabular}{|l|l|l|l|l|}
\hline Serial number & Speed $(\mathrm{m} / \mathbf{s})$ & Angular velocity (degree/s) & Speed error & Angular velocity error \\
\hline 1 & 2.284 & 302.6 & $0.16 \%$ & $0.88 \%$ \\
\hline 2 & 2.256 & 281.7 & $1.03 \%$ & $6.08 \%$ \\
\hline 3 & 2.256 & 285.9 & $1.03 \%$ & $4.69 \%$ \\
\hline
\end{tabular}




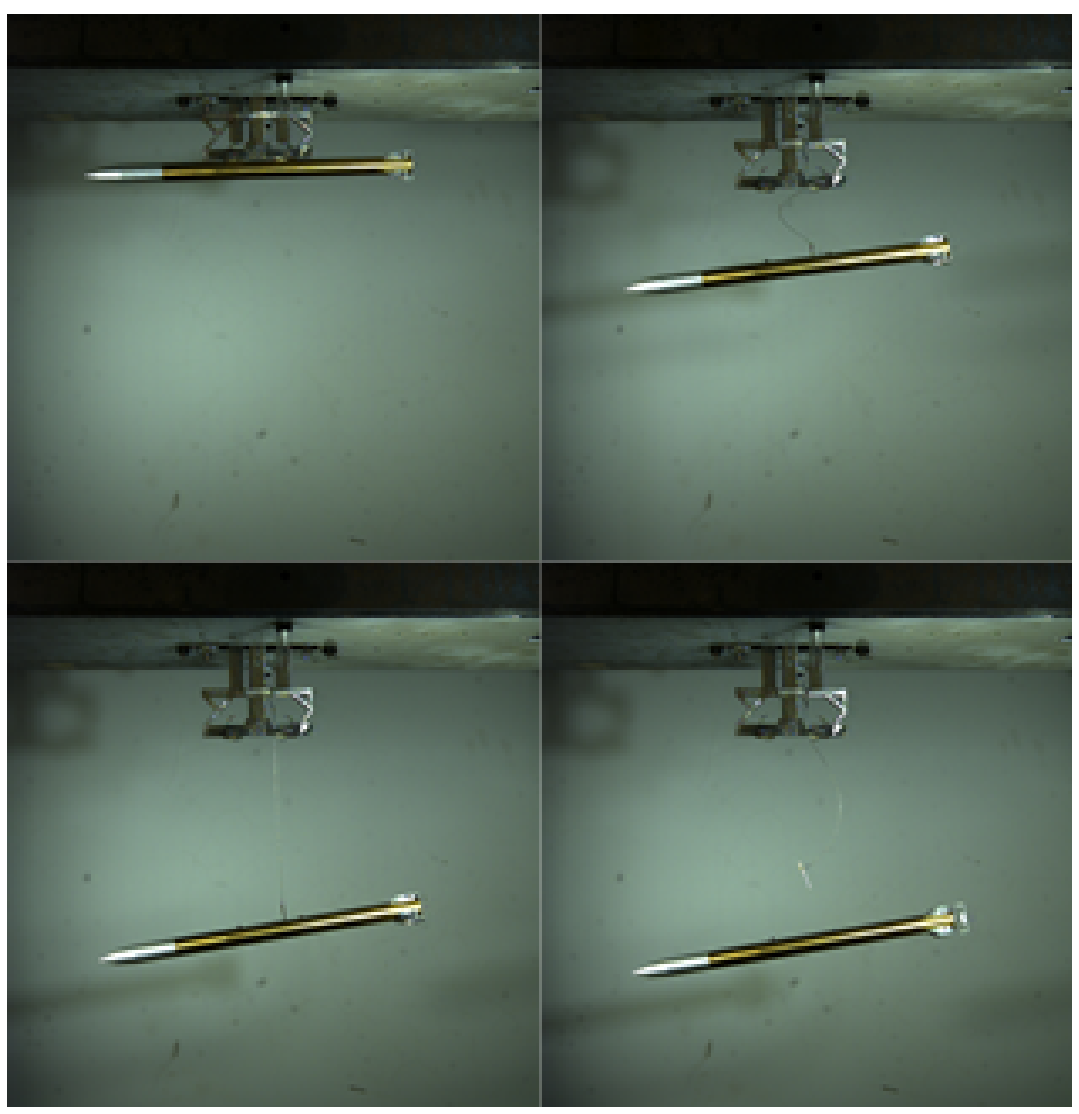

Figure 3: Horizontal folding rudder unfolding test.

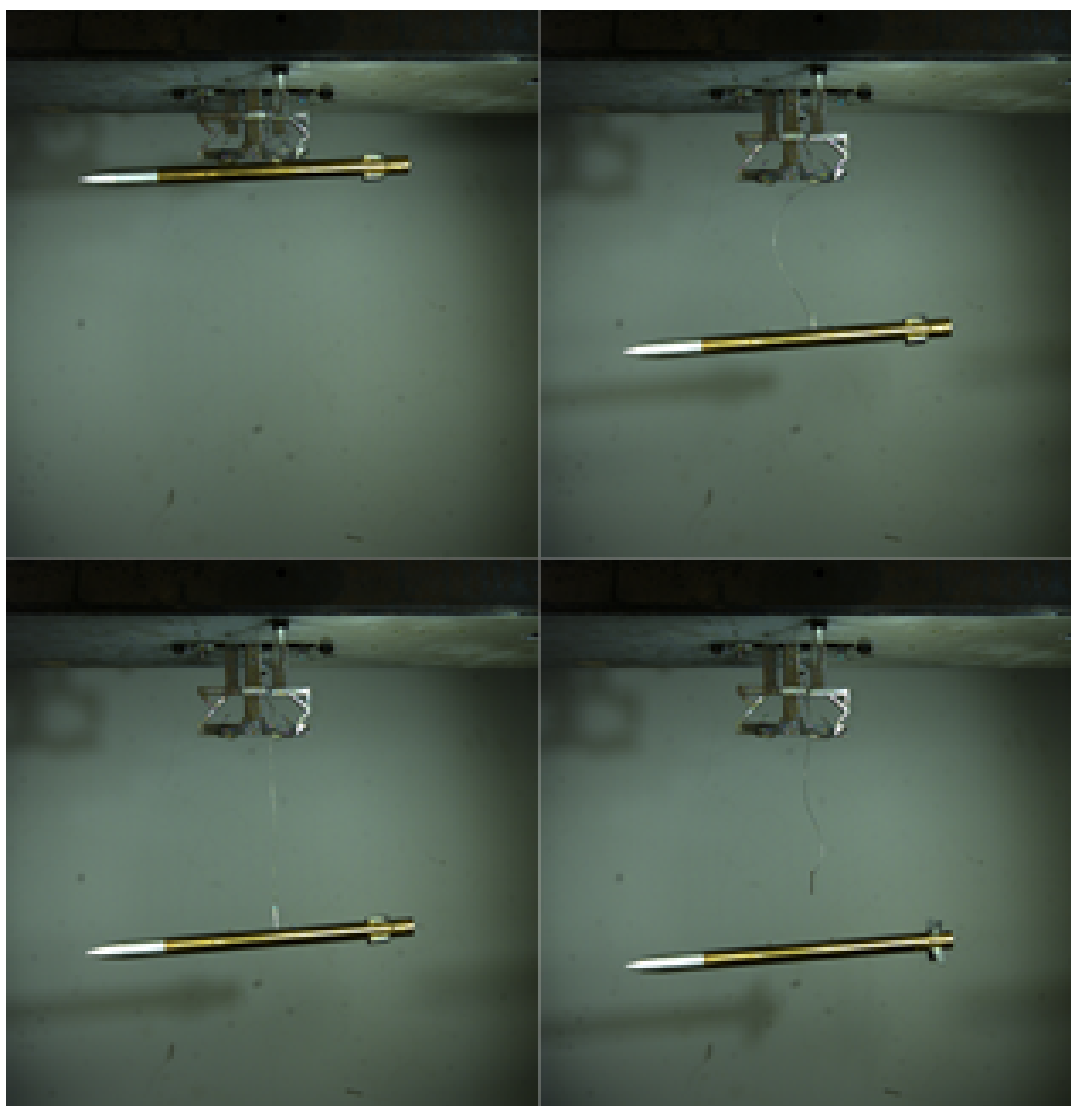

Figure 4: Vertical folding rudder expansion test. 
Table 2: The precision of attack angle.

\begin{tabular}{|l|l|l|l|}
\hline $\begin{array}{l}\text { Serial } \\
\text { number }\end{array}$ & $\begin{array}{l}\text { Truth } \\
\text { value } \\
\text { (degree) }\end{array}$ & $\begin{array}{l}\text { Identification } \\
\text { value (degree) }\end{array}$ & $\begin{array}{l}\text { Precision } \\
\text { (degree) }\end{array}$ \\
\hline-8.00 & -7.86 & -0.14 \\
\hline & -4.00 & -4.18 & 0.18 \\
\hline-2.00 & -2.14 & 0.14 \\
\hline 0.00 & 0.09 & -0.09 \\
\hline 2.00 & 1.90 & 0.10 \\
\hline 4.00 & 4.17 & -0.17 \\
\hline & 8.00 & 8.12 & -0.12 \\
\hline
\end{tabular}

\section{Reliability Test}

In order to verify the reliability of ejection technology, an ejection wind tunnel test was designed. The test site is shown in Figure 5.

The test has successfully completed the scheduled tasks, and all the parameters have met the requirements of setting technical specifications. The independent and continuous adjustment of ejection speed and angular velocity is realized, and the reliable ejection of separator with arbitrary wind loads and $\mathrm{Ma}$ is realized. As shown in Figure 6.

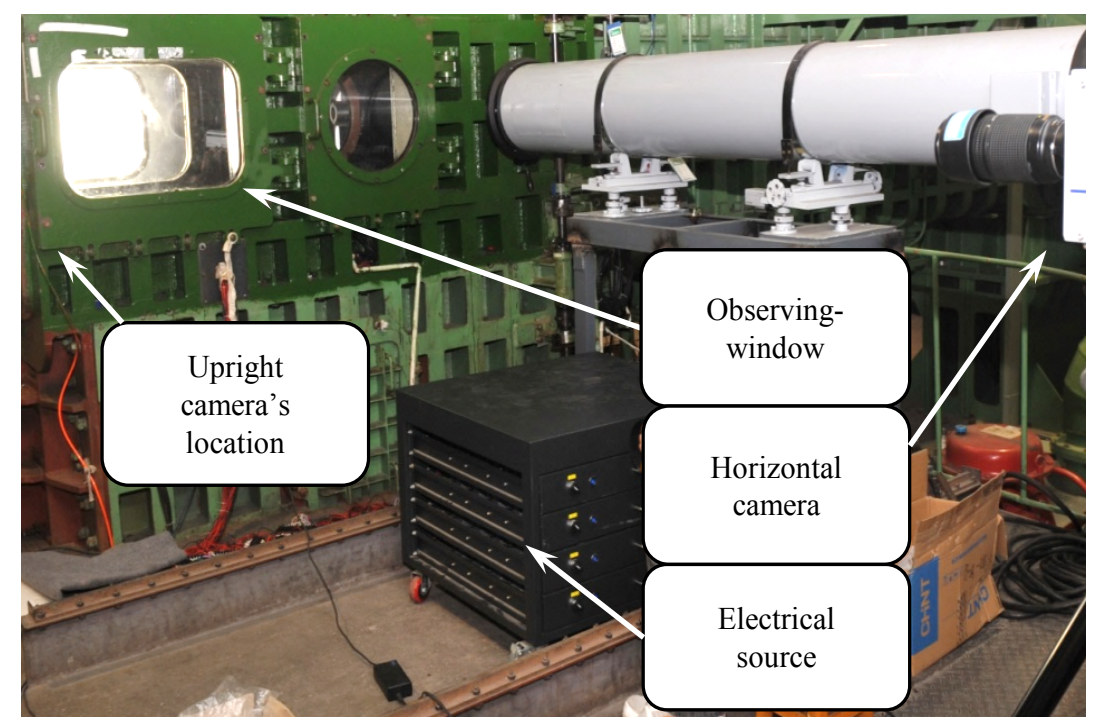

Figure 5: The test site.

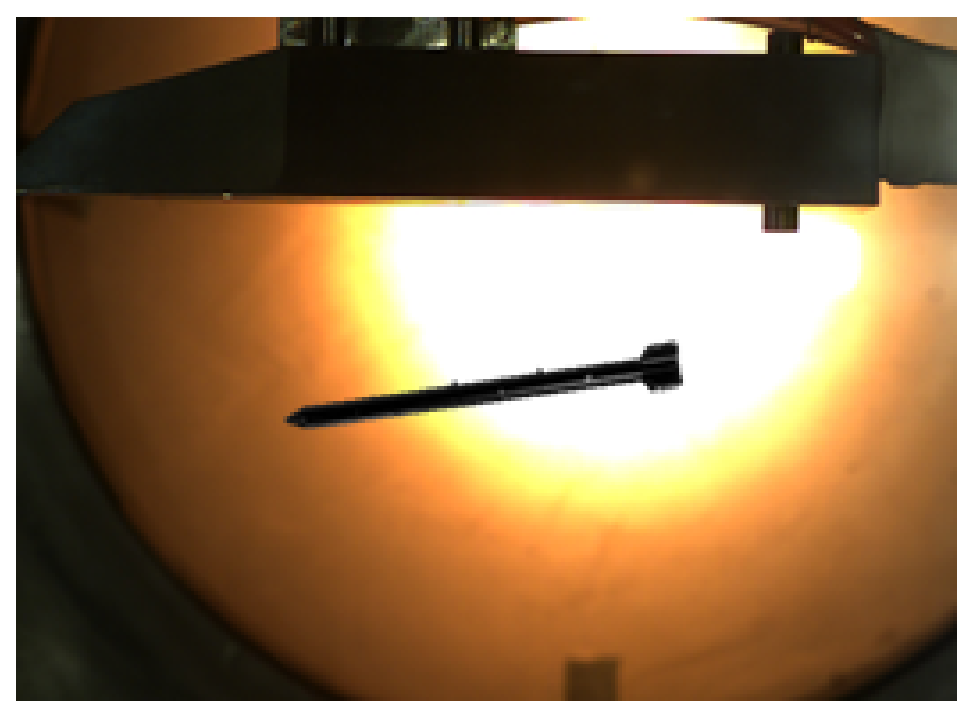

Figure 6: The picture shoot by horizontal camera. 

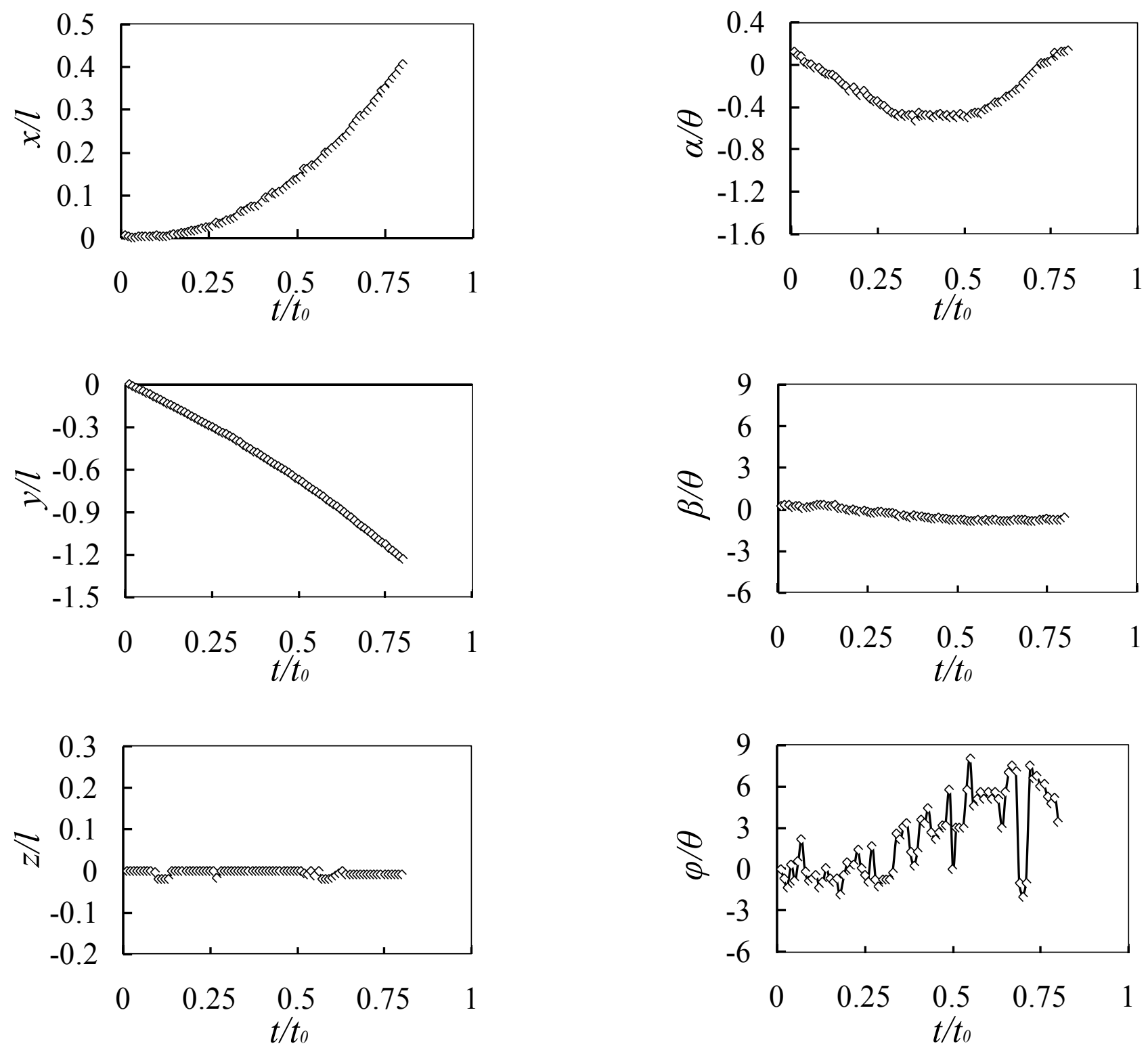

Figure 7: Curves of 6 DOF parameters changing with time.

As can be seen from Figure 7, the main trajectory of separation is to move to the lower and rear parts of the aircraft. The motion characteristics are as follows: lateral motion is not obvious; Yaw motion is not obvious; pitch motion is significant. Under the effect of initial bow angular velocity, the missile bows its head first, and then returns to zero under the effect of its own stability. The experimental model has certain roll characteristics.

\section{Conclusion}

In this paper, aiming at two different folding modes of the steering surface of the Separator, this paper designs and tests two kinds of testing techniques of horizontal folding and vertical folding of the rudder surface, which can ensure the selflock function before and after the rudder surface is unfolded. The folding and unfolding state is not affected by the impact of the wind tunnel starting and the turbulence. The deployment ability of the rudder at the predetermined position of the aircraft is achieved.

Through the use of the latest ejection scheme, the speed and angular velocity of the embedded separator are continuously adjustable, and the reliability of the technology is tested successfully in the subsurface hyper flow field. By improving the light path lighting system, the image clarity is higher, the image virtual shadow is reduced, and the identification of the Model 6 degree of freedom pa- 
rameters is favorable. The use of dual angle image acquisition technology, especially the layout of the upward looking optical path system, shows the details of the model movement to the greatest extent from many angles. The wind tunnel test is carried out for the launching mechanism.

\section{References}

1. Bjorge ST (2014) Flow around an object projected from a cavity into a supersonic freestream. AFIT/ GAE/ENY/04-M02.

2. Flora TJ (2012) Freedrop testing and CFD simulation of ice models from a cavity into supersonic flow. AFIT/GAE/ENY/12-S15.

3. Shipman J, Arunajatesan S, Cavallo PA, Birkbeck R, Sinha N, et al. (2007) Flow control for enhanced store separation. AIAA 2007-1239, Reston, USA.

4. Tang Shangqin, Huang Changqiang, Weng Xingwei (2013) The study on trajectory of separator separating from cavity with aerodynamic interference considered. Rockets, Separator and Guidance 33: 138142.

5. Shi Ai-ming, Ye Zheng-yin, Yang Yong-nian (2007) Calculation and analysis for aerodynamic loads acting on interior separator cabin as door. Aeronautical Computing Technique 37: 5-6.

6. Zhang Junxiang, Feng Jinfu, Yu Xinyi (2011) A new method for improving cavity flow. Rockets, Separator and Guidance 31: 165-168.

7. Xue Fei, Jin Xin, Wang Yuchao (2017) Experimental investigation on the high speed separator delivery from inter-nal separators bay. Acta Aeronautica et Astronautica Sinica 38: 120114.

8. Merrick JD (2014) Influence of Mach number and dynamic pressure on cavity tones and freedrop trajectories. AFIT-ENY-14-M-36.

9. Baker WB, Keen S Jr, Morgret C (2004) Validation of separator separation predictions using F/A-22 flight test results. AIAA 2004-6803, Reston, USA.

10. Finney LP (2010) Investigation of cavity flow effects on store separation trajectories. USNA-1531-1532.
11.Johnson RA, Stanek MJ, Grove JE (2008) Store separation trajectory deviations due to unsteady separators bay aerodynamics. AIAA 2008-188, Reston, USA.

12.Carter R, Lind R (2012) Parametric modeling for store separation aerodynamics using system identification. AIAA 2012-4510, Reston, USA.

13.Robert L Stallings Jr (1983) Store separation from cavities at supersonic flight speeds. Journal of Spacecraft and Rockets 20: 2.

14.Purdon ML, Hetreed CF, Hudson ML (2009) F-35 pre-flight store separation analyses: Innovative techniques for affordability. AIAA 2009-102, Reston, USA.

15.Zhu Shoutao, Cao Linping, Feng Puwen (2012) Simulation of separator separation from internal separator bay. Electronics Optics \& Control 19: 67-71.

16.(2005) Collaborative-design/control simulation in a separator-hidden launching gear and electro-hydraulic servo-system, 70-74.

17.Feng B i-ming, Nie Wan-sheng, Che Xue-ke (2009) Effect of initial conditions on separation trajectory of the internal separator. Rockets, Separator and Guidance 27: 62-65.

18.Chao C, Hai-he D (2012) Review on separator store safety separation technology of embedded ejection separators. Modern Defence Technology 40: 67-74.

19.Scott Keen K, Morgret C, Langham T, Baker W (2009) Trajectory simulations should match flight tests and other lessons learned in 30 years of store-separation analysis. AIAA-2009-99, Reston, USA.

20.Khana B, Knowles K, Saddington A (2009) Computational study of cavity flowfield at transonic speeds. AIAA-2009-701, Reston, USA.

21.A Fedorov, V Shalaev (2011) PC desktop aerodynamic models for store separation from separators bay cavities and related vortical processes. SYA 37: 1-20.

22.Yu Jian-Gang, Sang Wei-Min, Lei Xi-Wei (2011) Analysis of the flow characteristics and aerodynamic problems in cavity. Flight Dynamics 29: 29-32.

23.LI Zhou fu (2010) Wind tunnel special tests technique. Aviation Industry Press, China, 104-113. 